ORIGINAL ARTICLE

\title{
Willingness to Pay for Community-Based Healthcare Insurance Schemes in Developing Countries: A Case of Lahore, Pakistan
}

\author{
Akhtar Sana ${ }^{1 *}$, Fatima Rida ${ }^{1}$, Ishaq Tayyaba ${ }^{1}$, Mehmood Masooma ${ }^{1}$, Zulfqar \\ Ayesha $^{1}$, Akhtar Kalsoom ${ }^{2}$
}

OPEN ACCESS

Citation: Akhtar Sana, Fatima Rida, Ishaq Tayyaba, Mehmood Masooma, Zulfqar Ayesha, Akhtar Kalsoom. Willingness to Pay for Community Based Health Care Insurance Schemes in Developing Countries: A Case of Lahore, Pakistan. Ethiop J Health Sci. 2020; 30(1):135. doi:http://dx.doi.org/10.4314/ejhs.v30i1.17 Received: July 11, 2019

Accepted: August 24, 2019

Published: January 1, 2020

Copyright: (C2019. Akhtar S., et al. This is an open access article distributed under the terms of the Creative Commons Attribution License, which permits unrestricted use, distribution, and reproduction in any medium, provided the original author and source are credited. Funding: Nil

Competing Interests: The authors declare that this manuscript was approved by all authors in its form and that no competing interest exists.

Affiliation and Correspondence:

${ }^{1}$ Department of Environmental Sciences, Kinnaird College for Women, 93-Jail

Road, Lahore

${ }^{2}$ Department of Statistics, Kinnaird

College for Women, 93-Jail Road, Lahore

Correspondence: Sana Akhtar

*Email: sanakhtar23@gmail.com

\section{ABSTRACT}

BACKGROUND: Healthcare costs and poverty are significant barriers to achieving universal access to healthcare. Thus, Community-Based Health Insurance Schemes (CBHIS) are regarded as an influential instrument for providing access to healthcare. For this purpose, this study was carried out in order to assess the community's Willingness to Pay (WTP) for CBHIS and its determinants among the residents of Lahore City.

METHODS: A cross-sectional study was adopted during the period of May 2018 to August 2018 to conduct a standardized questionnaire survey among targeted population of Lahore. A total of 250 households from lower, middle and upper-middle-class areas were approached randomly from which 200 participated in the survey, rendering a response rate of $90.9 \%$. Sample size was determined by using single population proportion formula assuming 5\% margin of error and 95\% Confidence Interval (CI). Moreover, multiple regression analysis, Pearson's correlation and t-test were employed to determine relationships between different variables affecting WTP.

RESULTS: Sixty-four percent of the respondents were willing to pay for CBHIS. Among the remaining thirty-six\% of unwilling the community, income level $(p<0.05, C I=0.34$ to 1.11$)$ and education level ( $p<0.05, C I=0.52-1.37)$ were significant predictors of WTP. Moreover, strong positive relation $(p<0.05)$ between people's awareness and WTP for CBHIS was witnessed. The findings further suggested that the larger population of the willing community was not willing to pay more than 5000 Rs annually.

CONCLUSION: Henceawareness level of the community regarding the benefits of CBHIS is a major hindrance. The key policy priority is to increase the community's awareness regarding the benefits of CBHIS and to increase willingness to pay rate among public.

KEYWORDS: Awareness, Community Based Health Insurance System (CBHIS), Willingness to Pay (WTP), Lahore and questionnaire 


\section{INTRODUCTION}

Poverty and healthcare costs are not worthy barriers to achieving health care facilities. Due to lack of health insurance, poor families having confined resources face many problems because of health care costs being paid Out of Pocket Payment (OPP) (1). Due to low income or absence of medical services, poor families especially those living in low socioeconomic areas are unable to accomplish health services or medical care. Whenever they get ill or unhealthy, they usually borrow money from friends or families for their treatment because they do not have sufficient money for treatment. Another way to get rid of OPP for treatment includes Community-Based Health Insurance Schemes (CBHIS). CBHIS is important for protecting poor or even middle-income families from sickness or diseases. Advance payment of medical services, control of community and membership of volunteers are the three most important parts of communitybased health insurance. For accessing worldwide healthcare or medical services in poor countries, many international development agencies work on community-based health insurance (2).

For the provision of quality healthcare services even in the face of shrinking budgets and institutional hitches, the government and donor agencies in developing countries are now involved in the implementation of various Health-Based Insurance Schemes (3). Financing of healthcare costs poses challenges to the low and middle-class countries, especially when limited taxation policies and complex management of healthcare insurance schemes are significant barriers that are the main causes of inadequate health expenditures per capita in such countries. Community's contribution to enrolling in such schemes proves to be an opportunity for the residents to receive good healthcare insurance coverage especially in low and middle-income countries (4).

We can find a wide number of international as well as national level studies that have been carried out to assess whether the population on the global scale living in low socioeconomic communities are willing to pay for CBHIS. In the developing countries, people's awareness about health insurance plays an important role because they do not contain any policy on health insurance. A study was done to estimate the willingness to pay for healthcare insurance facilities among three different categories of job workers in Bangladesh. Regression Model analysis was used to identify the major determinants of Willingness to Pay (WTP). With the increase in $1 \%$ of the monthly income, WTP increased up to $0.196 \%$. This means as the salary of the workers increased, their WTP also increased; this corresponds to the workers who had enough pays but are still not willing to pay for health insurance schemes. The main reason lied in the Awareness Level (Perceptions and Mind-Sets) and the education level of the respective workers. As $90 \%$ of the workers' education statuses were less than the primary level. So, it was concluded that differences in socioeconomic status explain the magnitudes of WTP (5). In the literature, lowincome level, unreliability towards the scheme and lack of information due to insufficient education within the households were also major reasons for low enrolment for the scheme (6).

According to a local level study done in rural areas of Faisalabad where people beneficiaries of the Benazir Income Support Program (BISP) have initiated a pilot health insurance program Waseelae-Sehat (WS). However, the WS program only focused on the poor and middle-class community of the area. But when the community's willingness was kept in view, $80 \%$ of the community disagreed to pay. Hence, OPP proves to be a burden for these households where there are existing problems of financials crises (7). From the literature review, it is clear that the WTP for health insurance mostly depends on education level, income and many other socioeconomic factors.

Currently, Pakistan has a high prevalence of mortality rates compared to the regional average. According to the burden of disease report, almost $64 \%$ of the population dies due to communicable diseases while $26 \%$ die due to non-communicable diseases and the remaining $10 \%$ due to injuries and accidents. Moreover, with the increasing population and urbanization, healthcare costs are more impoverishing than ever before. Generally, almost all hospitalizations, including public hospitals, lead to catastrophic health expenditures and accessing treatment from private providers leads to high household treatment costs. In such cases, health insurance schemes play an important role in

DOI: http://dx.doi.org/10.4314/ejhs.v30i1.17 
reducing the high costs of healthcare on the general public and serves as a proxy indicator for financial fairness and provide financial protection to the households against healthcare costs. It saves OPP expenditures of the poor communities by increasingly channelizing "community financing" schemes in order to cover the costs of communitybased health delivery. Along with that, such health insurance schemes turn unpredictable health expenditures into predictable insurance payments. Unfortunately, there is little awareness and complete ignorance towards such schemes among the majority population (poor and middle class) of Pakistan. Consequently, this reduces the community's' willingness to spend on CBHIS $(8,9)$.

This underscores the need for governmental policymakers and other researchers to key into the findings of the present study and create more community awareness, stakeholder sensitization and eventually stimulates commencement of CBHIS as per demand in the country (10). Presently, a number of healthcare insurance programs are in progress within Lahore City. The very high share of
OPP expenditure in total and private health expenditure, high morbidity, disability and poverty and low access to healthcare make a valid ground of willingness for the provision of some health insurance scheme for the general public of Lahore City. Keeping in view the health-associated vulnerability among the inhabitants of Lahore, awareness on the importance of CBHIS becomes an urgent national need. The main interest to study this topic is to investigate whether the population of Lahore City is willing to pay for the CommunityBased Health Care Insurance Program as well as to determine the factors that are likely to influence household willingness to participate. Moreover, this study will also help to determine the level of awareness among the locals of the community for participating actively in CBHIS.

\section{MATERIALS AND METHODS}

Study Area: Different areas consisting of lower middle class to upper-middle population of Lahore City were selected randomly for the survey. Location map of the study area is given in Figure 1.
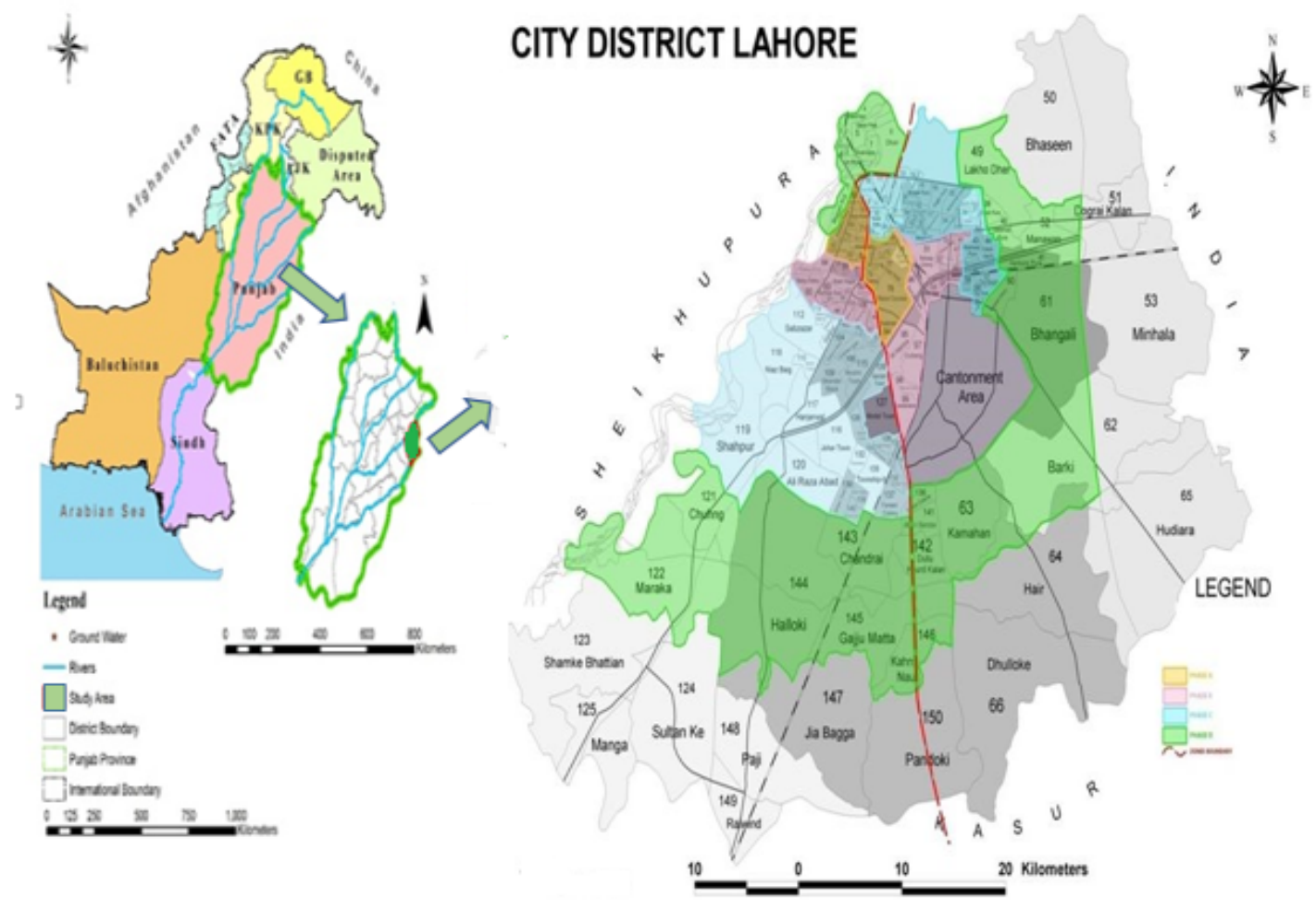

Figure 1: Location Map of the study area 
Lahore is considered as the capital city of province Punjab. It is the second-largest and most populous city in Pakistan; it lies along the west bank of River Ravi and spreads over an area of $1,772 \mathrm{~km}^{2}$ with an estimated population of around 12,500,000 (11). The respondent population of the city mostly constituted lower middle class to upper- middleclass residents with moderate income levels. Occupation status of the respondents of the area varies with income levels.

Health care services of the study area: The health service in the study area is generally divided into two categories: Primary Health Care (PHC), that is fully financed by the government, and is delivered almost free of charge to all residents, and Treatment Services (TS) that are offered by a large number of hospitals (mostly public hospitals) and many private ambulatory service outlets including pharmacies, physicians' offices, diagnostic services etc. The cost of these treatment services is usually incurred by patients, which can be substantial if they are not insured, and especially if the services are offered by the private sector (12).

Data collection: This cross-sectional study was conducted from May 2018 to August 2018. A total of 250 households from lower middle class and upper middle-class areas were approached randomly from which 200 participated in the survey, thus making a response rate of $90.9 \%$.

The sample size was determined by using a single population proportion formula assuming marginal of error of $5 \%(\mathrm{~d}=0.05)$ with a significance level of 0.05 . The degree of the confidence interval was $95 \%(Z=1.96)$ by using a finite population correction formula and adding $10 \%$ for potential non-response. This yielded a sample size of 200 participants (14). Random sampling technique was employed to select study participants. Only one family member who knew the most about the family expenses was chosen to become the respondents ]

First of all, the respondents were familiarized with the concept of CBHIS so that they could answer the questions easily. Data collection was carried out with the help of a standardized pretested questionnaire which consisted of four different sections. The first is the demographic section (which included the basic information like name, gender, marital status, education, occupation and income level of the residents). The second section included health status of the family. The third section consisted of the existing knowledge of the respondents about CBHIS of the respondents. The fourth section consists of respondents willing to pay for CBHIS (15).

Data analysis: The questionnaire filled by respondents was checked for consistency and completeness, and data were entry was performed for analysis into Statistical Package for Social Sciences (SPSS) version 21.0. Different statistical tests like independent t-test, Pearson's correlation and multiple regression analysis were employed to determine the relationship between independent and dependent variables. The dependent variable was WTP while the independent variables were respondents' gender, education, monthly income and occupation.

Multiple regression analysis was carried out to determine associations of selected variables with dependent variables, and p-value of less than or equal to 0.05 was taken as a cut-off point to candidate variables. Independent predictors were determined using the adjusted odds ratio with 95\% confidence interval with the 5\% margin of error. Additionally, Pearson correlation was employed to study the relationship between respondents' awareness level and their willingness to join CBHIS. The relationship was considered significant if $\mathrm{p}$ value was less than or equal to 0.05 . An independent sample t-test was used to determine the relationship between the health status of the families with their level of satisfaction. The results were presented in the form of figures and tables based on the type of data.

Respondents were requested for their verbal consent to participate in the study. For confidentiality, the names of the respondents were not written on the copies of the questionnaire. Moreover, no findings which could identify individual respondents were published $(10,13)$. 


\section{RESULTS}

The figure (fig.2) shows that 128 respondents (64\%) said they were willing to join CBHIS while 72 respondents (36\%) said they were not willing to join CBHIS.

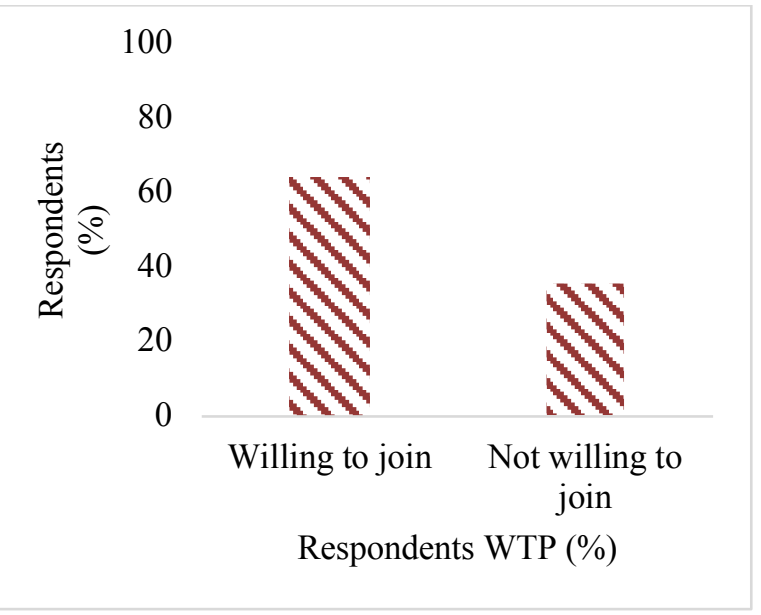

Figure 2: Willingness to join the CBHIS
Figure 3 shows that 72 respondents (36\%) wanted to join the CBHIS to get free access to medical care, $41(20 \%)$ wanted to join in order to help others, 38 $(19 \%)$ wanted to join for achieving security and peace of mind and $49(25 \%)$ wanted to join CBHIS since they faced health problem frequently.

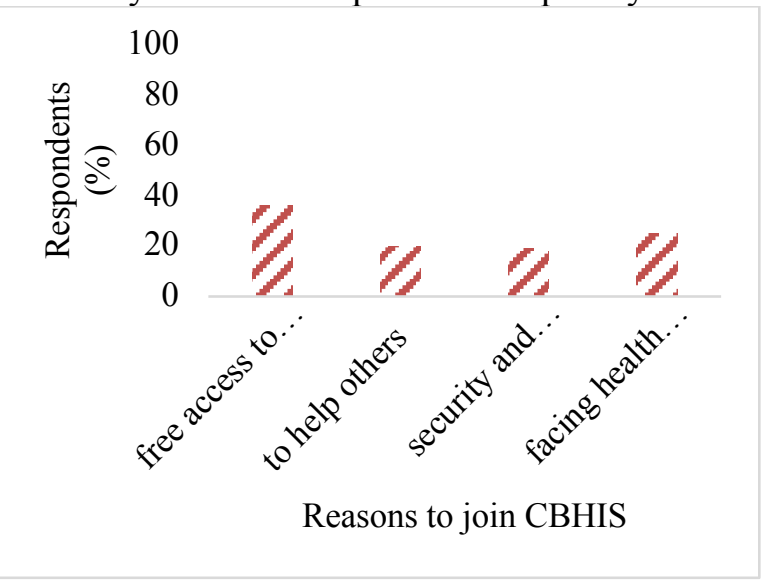

Figure 3: Reason to join the $C B H$

Table 1: Multiple regression analysis showing model summary of the relationship between joining CBHIS with predictors variables

\begin{tabular}{|c|c|c|c|c|c|c|c|c|c|}
\hline & $\begin{array}{l}\text { Mean } \\
\text { Square }\end{array}$ & $\mathbf{F}$ & Df & Sig. & F Change & $\begin{array}{c}\text { Sig. F } \\
\text { Change }\end{array}$ & $\begin{array}{l}\text { Adjusted } \\
\text { R square }\end{array}$ & \multicolumn{2}{|c|}{$\begin{array}{l}\text { 95\% Confidence } \\
\text { Interval }\end{array}$} \\
\hline \multirow[t]{3}{*}{ Regression } & 2.357 & 12.619 & 4 & 0.00 & \multirow{3}{*}{$\begin{array}{c}12.61 \\
\text { Standardized } \\
\text { Coefficients } \\
\quad \text { Beta }\end{array}$} & 0.00 & 0.19 & \multirow{3}{*}{ Lower } & \multirow{3}{*}{ Upper } \\
\hline & Model & & \multicolumn{2}{|c|}{$\begin{array}{l}\text { Unstandardized } \\
\text { Coefficients }\end{array}$} & & & & & \\
\hline & & & $\begin{array}{c}\text { Coef } \\
\text { B }\end{array}$ & $\begin{array}{l}\text { ients } \\
\text { St.Error }\end{array}$ & & t & Sig. & & \\
\hline Gender & 1.58 & .588 & .015 & .053 & .018 & .276 & 0.78 & 0.5 & 1.37 \\
\hline Education & 4.51 & 1.669 & 0.14 & .022 & .048 & .643 & 0.03 & 0.52 & 1.37 \\
\hline $\begin{array}{l}\text { Monthly } \\
\text { Income }\end{array}$ & 2.38 & 1.037 & 1.95 & .422 & .422 & 6.153 & 0.00 & 0.34 & 1.11 \\
\hline Occupation & 5.03 & 1.762 & .014 & .051 & .051 & .714 & 0.47 & 0.45 & 1.17 \\
\hline
\end{tabular}

Multiple Regression Analysis was conducted to determine the effect of linear combination of predictors like gender, education level, monthly income and occupation level on willingness to pay for health insurance Schemes.

Sig. F change $0<0.05$ shows the influence of these variables can be predicted on WTP.

Sig. value of Income level $p=0.00<0.05$ shows income level significantly predicts WTP.

Sig. value of Education level $\mathrm{p}=0.03<0.05$, shows Education Level significantly predicts WTP.

The value of adjusted R square is 0.19 this indicates $19 \%$ of the variance in WTP. 
Table 2: Pearson's Correlation showing relationship between Respondents Awareness Level and Willingness to join CBHIS

\begin{tabular}{|c|c|c|c|c|}
\hline & & Willingness to join & Awareness & Level \\
\hline \multirow{3}{*}{$\begin{array}{c}\text { Willingness to join } \\
\text { CBHIS }\end{array}$} & & CBHIS & & \\
\hline & Pearson Correlation & 1 & $0.149^{* * *}$ & \\
\hline & Sig. (2-tailed) & & 0.03 & \\
\hline \multirow{4}{*}{ Awareness Level } & $\mathrm{N}$ & 200 & 200 & \\
\hline & Pearson Correlation & $.149^{* *}$ & 1 & \\
\hline & Sig. (2-tailed) & .036 & & \\
\hline & $\mathrm{N}$ & 200 & 200 & \\
\hline
\end{tabular}

*Correlation is significant at the 0.05 level (2-tailed)

A strong statistically significant positive increases, the community's willingness to pay also relationship $(\mathrm{p}<0.05)$ was found between increases. A p-value $<0.05$ is considered to declare respondents' awareness and willingness to join a statistically significant association with dependent CBHIS (Table:1). As the level of awareness and selected independent variables.

Table 3: An independent t-test showing health statuses of the family with its level of satisfaction

\begin{tabular}{lcccc}
\hline & \multicolumn{2}{l}{ Respondents Level of Satisfaction about Health } & & df \\
\cline { 2 - 3 } & Satisfactory & Unsatisfactory & & \\
\hline $\begin{array}{l}\text { Health Status } \\
\text { of family }\end{array}$ & 134 & 66 & $-2.27^{* *}$ & 78 \\
\hline
\end{tabular}

Note. ${ }^{* *} \mathrm{p}<.01, \mathrm{df}=$ degree of freedom

An independent sample t-test was conducted (table:2) to compare the health status of respondent's families. Significant relationship was obtained for Satisfactory $[\mathrm{M}=134, \mathrm{SD}=0.475]$ and Unsatisfactory health status $[\mathrm{M}=66, \mathrm{SD}=0.51 ; \mathrm{t}$ $(78)=-2.27, \mathrm{p}=.01]$.

\section{DISCUSSION}

The results indicated that a large proportion of residents $(64 \%)$ was willing to pay for CBHIS. They believed that health insurance may help to improve the quality of care provided by public health care facilities, gives them free access to medical care and gives them security and peace of mind in case of frequently facing health problems. Moreover, a major problem observed in the survey was that people were not willing to pay the desired range of money needed to enroll in a CBHIS. Even the willing community was not willing to pay more than $5000 \mathrm{Rs}$ on the bi-annual rate because of the moderate-income level as OPP, which proves to be a financial burden and a major hindrance for them. These findings are similar to the study done by the Waseela-e-Sehat (WS) program in which OPP proved to be a major barrier in enrolling in CBHIS and in paying desired range of payments for health care insurance programs that proved to be a financial burden for the community as well (7).

The role of a household's economic status is very important in payment of healthcare insurance premiums. The higher the economic status, the more the households would be at ease to pay insurance premiums compared to low-level income individuals. This is similar to a study found that higher-income households are willing to pay (6). The results of the multiple regression analysis also revealed a significant increase in community's income level that will increase the community's WTP $(p<0.05)$. Usually, higher-income residents have enough resources to purchase health insurance schemes and to protect their income/wealth against mishaps (illness/injury/accident). Individuals would like to have insurance coverage to compensate for the loss of income/wealth during bad events and maintain the same level of utility when they become ill. Comparatively, the middle-class residents stated that they do not have enough resources and that they 
need to take financial assistance by relatives or have to take loans from their jobs in such cases.

. Education plays an important role in improving health status by creating awareness of health maintenance options. Education/awareness can identify the means to promote and protect health. Health insurance is one of the important options to protect health and to mitigate the effects of rising costs of healthcare. This is similar to the study carried out in Bangladesh among the informal workers in which the main reasonfor decreased WTP was lack of awareness level (perceptions and mindsets) and education level of the workers even those with enough salaries but still not willing to pay for health insurance schemes (5).

Further, the education level $(\mathrm{p}<0.05)$ of the respondents (whether male or female) proved to be a significant parameter in the study. The education level of the respondents had a positive relationship with the WTP, an increase in the education level causes an increase in WTP. Most of the respondents in the study had an education level greater than the intermediate level.

Female residents of the study area mostly participated in the survey, but the results of multiple regression analysis indicated no significant difference between males' and females' level of willingness to purchase health insurance. Results of multiple regression analysis also indicated no significant difference between male and female respondents' level of willingness to purchase health insurance as no significant distinction in their thoughts was observed for WTP. Moreover, it was hypothesized that the respondents with good employment status will have more WTP but the results of multiple regression analysis do, not support this hypothesis by showing an insignificant relationship between occupation level and WTP of the respondents.

Awareness about health insurance may influence the demand for health insurance. Findings showed that well aware households were almost two times more willing to register for health insurance compared to the unaware ones. As the results of the Pearson Correlation proved this point $(\mathrm{p}<0.05)$, if the awareness of people regarding joining CBHIS increases, their willingness to join CBHIS also increases.

DOI: http://dx.doi.org/10.4314/ejhs.v30i1.17
Illness in a household affects the need for healthcare and hence may influence the demand for health insurance. It was anticipated that respondents whose households had better health statuses shall be less willing to pay than those in worse health. These assumptions were quite comparable with results of independent t-test which showed significant differences between the respondents whose level of health was satisfactory $[\mathrm{M}=134, \mathrm{SD}=0.475]$ and those were not satisfied with the health status $[\mathrm{M}=$ $66, \mathrm{SD}=0.51 ; \mathrm{t}(78)=-2.27, \mathrm{p}=.01]$. The higher mean is for the respondents who had unsatisfactory health status. These results further showed that most of the households with unsatisfactory health status were not willing to pay because they had already spent significant amount on the treatment funds; so they are not willing to pay more (16).

Out of 200 households, a few of the respondents had a member in their households suffering from any certain sort of disease. The willingness to obtain health insurance increases if there is an ill member of the household. In addition, the nature or severity of illness may also affect the decision to seek healthcare and the need for health insurance. Other factors which proved to be the significantly influencing WTP level of the respondents include the mindsets of the respondents about these schemes as a wastage of money and regards these schemes as OPP whereas others do not trust the health insurance providers which might impact enrollment statuses of the schemes (17).

In conclusion, this study unveiled some different and significant facts about the willingness of households to contribute to CBHIS. The present study fills the knowledge gap in assessing the willingness of households for health insurance, the amount of premium and cost of healthcare of households. The results showed that extensive percentages of uninsured households were willing to pay for community-based health insurance. Awareness, economic status, and the nature of illness of households were some significant factors in WTP for health insurance. Generally, these insurance schemes are considered as an influential instrument for providing the access to health, can serve as a reliable income for healthcare providers, may help in cost recovery for the health sector and protect people from high OPP spending in the residents of Lahore in a more equitable way. 
Moreover, the government should initiate awareness programs for low-income earners for enhancing the demand for CBHIS. Therefore, people with moderate and lower socioeconomic status must be involved from the beginning. This will certainly increase their understanding and contribution to the plan. Additionally, the government should provide funds for such type of schemes so that monetary pool can be generated for the sustainability of the CBHIS.

\section{ACKNOWLEDGMENTS}

The author would like to thank Department of Environmental Sciences, Kinnaird College for Women Lahore, Pakistan

\section{REFERENCES}

1. Jahangeer A, ul Haq R. Willingness to Purchase Health Insurance in Pakistan. Pakistan Institute of Development Economics Islamabad.2015.

2. Gottret P, Schieber G. Health financing revisited: a practitioner's guide. The World Bank; 2006 Mar 30.

3. Tundui C, Macha R. Social capital and willingness to pay for community based health insurance: Empirical evidence from rural Tanzania. J Financ Econ 2014; 2:50-67.

4. Wang H, Yip W, Zhang L, Wang L, Hsiao W. Community-based health insurance in poor rural China: the distribution of net benefits. Health Policy Plan 2005; 20:366-74.

5. Nosratnejad S, Rashidian A, Mehrara M, Sari AA, Mahdavi G, Moeini M. Willingness To Pay for Social Health Insurance in Iran. Glob J Health Sci 2014; 6:154.

6. Mtei G, Mulligan J. Community health funds in Tanzania: A literature review. Ifakara Health Research and Development Centre, Ifakara. 2007.

7. Msuya JM, Jütting JP, Asfaw A. Impacts of Community Health Insurance Schemes on health care provision in rural Tanzania. ZEF Discussion Papers on Development Policy; 2004.

8. Kusuma YS, Pal M, Babu BV. Health Insurance: Awareness, Utilization, and its Determinants among the Urban Poor in Delhi, India. JEGH. $2018 ; 8: 69$.

9. Dong H, Kouyate B, Cairns J, Sauerborn R. Differential willingness of household heads to pay community-based health insurance premia for themselves and other household members. Health Policy Plan. 2004;19:120-6.

10. Onwujekwe O, Okereke E, Onoka C, Uzochukwu B, Kirigia J, Petu A. Willingness to pay for communitybased health insurance in Nigeria: do economic status and place of residence matter?. Health Policy Plan. $2009 ; 25: 155-61$.

11. Ali Z, Rauf A, Sidra S, Nasir ZA, Colbeck I. Air quality (particulate matter) at heavy traffic sites in Lahore, Pakistan. J. Anim. Plant Sci 2015;25:644-8.

12. Majrooh MA, Hasnain S, Akram J, Siddiqui A, Shah F, Memon Z. Accessibility of antenatal services at primary healthcare facilities in Punjab, Pakistan. $J$ Pak Med Assoc 2013;63:60.

13. Basaza R, Kyasiimire EP, Namyalo PK, Kawooya A, Nnamulondo P, Alier KP. Willingness to pay for Community Health Insurance among taxi drivers in Kampala City, Uganda: a contingent evaluation. Risk Manag Healthc Policy.2019;12:133.

14. Wang Y, Zhang YS. Air quality assessment by contingent valuation in Ji'nan, China. $J$ Environ Manage 2009; 90:1022-9.

15. Dong H, Kouyate B, Cairns J, Mugisha F, Sauerborn R. Willingness-to-pay for community-based insurance in Burkina Faso. Health Econ 2003; 12:849-62.

16. Mathiyazaghan K. Willingness to pay for rural health insurance through community participation in India. Int J Health Plan M 1998; 13:47-67.

17. Bärnighausen $T$, Liu $Y$, Zhang $X$, Sauerborn R. Willingness to pay for social health insurance among informal sector workers in Wuhan, China: a contingent valuation study. BMC Health Serv Res 2007;7:114.

18. Dror DM, Radermacher R, Koren R. Willingness to pay for health insurance among rural and poor persons: Field evidence from seven micro health insurance units in India. Health policy. $2007 ; 82: 12$.

19. Maluka SO, Bukagile G. Implementation of Community Health Fund in Tanzania: why do some districts perform better than others?. Int J Health Plan M 2014 ;29:368-82.

20. Lang HC, Lai MS. Willingness to pay to sustain and expand National Health Insurance services in Taiwan. BMC Health Serv Res. 2008; 8:261. 